\title{
Reflexiones sobre la violencia y vulnerabilidad en México*
}

Introducción

El propósito de este artículo es plantear una explicación sociológica de la violencia ejercida por el Estado mexicano en su combate contra la llamada delincuencia organizada. Se observa que la violencia estatal puede considerarse un modo de introducción de nuevas reglas, cuyo objetivo es el no reconocimiento de las prácticas informales de ciertos grupos organizados con poder. Se estudia como el orden estatal se impone en un contexto de vulnerabilidad social, y que la seguridad pública basada en métodos tecnológicos de control de interacciones colectivas debilita los derechos civiles al tiempo que el Estado desusa las políticas sociales para evitar la expansión de la pobreza y la miseria, consideradas las causas de la multiplicación de actividades delictivas.

Palabras clave: vulnerabilidad, criminalización, estado de excepción, violencia estructural, violencia directa.

- Docente-investigador del Centro de Investigaciones Económicas, Administrativas y Sociales del Instituto Politécnico Nacional. Miembro del Sistema Nacional de Investigadores, nivel II miguelviteperez@yahoo.com.mx lidad y violencia. Se busca explicar, de manera general, el estallido de violencia propiciado por el ejecutivo federal panista desde el momento en que declaró la guerra contra el narcotráfico.

Vulnerabilidad social es un concepto que permite explicar los cambios operados en la organización social por las transformaciones del Estado de bienestar; tales como una débil regulación estatal de la economía capitalista y la ruptura paulatina de los lazos establecidos entre el sistema de bienestar estatal y el trabajo asalariado. Esta ruptura ha sido considerada como la causa que haya aumentado el número de individuos que sufren una situación de vulnerabilidad; misma que se caracteriza por la inestabilidad laboral y las consecuentes incertidumbre y exclusión. Es decir, la figura de la sociedad protectora del individuo es anu-

*A la memoria de José Luis Piñeyro (1948-20|4). 
lada; los individuos quedan en estado de precariedad, con ínfimos derechos ciudadanos y sin una entidad (Estado) responsable de "sacarlos" de esa situación de invalidez social (Castel y Haroche, 2003).

Ante el desorden provocado por una economía capitalista autoregulada y acompañada del debilitamiento de las protecciones sociales gestionadas desde el Estado, se produce una penalización de la pobreza al convertirse en un problema de inestabilidad social por la multiplicación de las actividades criminales (Wacquant, 2010). El Estado criminaliza la pobreza y la miseria y construye así enemigos; una figura ante la cual puede justificar el uso de la fuerza policial y del posterior castigo, sea encierro o despojo de la vida (véase Caldeira, 2010). La capacidad estatal para criminalizar se relaciona con su poder para actuar al margen del orden legal y, al mismo tiempo, para transformar excepciones en reglas, conservando estas por prolongados espacios de tiempo. Entonces resulta más útil hablar de situaciones de vulnerabilidad $\mathrm{y}$, por tal motivo, la violencia, desde mi punto de vista, depende de diferentes situaciones y no puede ser definida solamente por la confrontación directa, aunque los medios de comunicación se enfoquen más en las consecuencias derivadas del enfrentamiento directo (Lara Klahr y Barata, 2009).

Existen diversas situaciones de vulnerabilidad y violencia que hacen imposible elaborar generalizaciones, puesto que responden a interacciones particulares entre los individuos. Sin embargo, desde una perspectiva sistémica, la violencia tiene sus manifestaciones en el desempleo y en la precariedad laboral, así como en la ausencia de derechos sociales, considerados como protecciones gestionadas por el Estado. Por otro lado, la violencia es un evento -y no una situación permanente- que puede aparecer en un momento de la reproducción de las relaciones sociales y, por lo tanto, no las determina ni tiene solo como causa, por ejemplo, la pobreza. 
Reflexiones sobre la violencia y vulnerabilidad en México

Pero tal como se intenta explicar aquí la violencia estatal, es necesario introducir la noción de estado de excepción; sobre todo en el caso mexicano, en el cual las instituciones de seguridad pública han sido facilitadores de los negocios ilícitos del narcotráfico.

La alternancia partidista, que a partir del año 2000 se presentó en la presidencia, ha favorecido la autonomía de los poderes locales, pero no ha desterrado las prácticas autoritarias; aunque sí ha atomizado el poder, lo cual se ha reflejado en los acuerdos específicos entre autoridades locales y narcotraficantes. Desde un punto de vista metodológico, en este trabajo se parte del supuesto de que la realidad social es una construcción en la cual intervienen diferentes intereses. En el caso que nos ocupa, la criminalización desde el poder político de las actividades del narcotráfico ha sido resultado de la elaboración de un enemigo, el cual es presentado como un peligro para la estabilidad social (Gergen y Gergen, 2011).

El trabajo se divide en cuatro partes. En la primera se explica que la vulnerabilidad social es resultado de un proceso relacionado con la crisis del Estado de bienestar y de la sociedad organizada a través del trabajo asalariado. En la segunda, se hace una interpretación crítica de la relación entre la vulnerabilidad y la violencia. En la tercera, se analiza el estado de excepción mexicano, para comprender la criminalización de las actividades del narcotráfico. Finalmente, se presenta una reflexión general sobre el tema estudiado.

\section{La vulnerabilidad social desde la sociología}

El Estado se puede definir a través de las diferentes prácticas de su personal, las cuales no se limitan al uso de la fuerza; además, la frontera social que separa lo público de lo privado permite confirmar la autoridad estatal frente a 
los intereses de la sociedad. Esto significa que la fortaleza o debilidad del Estado no depende de la cantidad de recursos económicos ni humanos que controla, ni mucho menos de su capacidad militar o técnica, sino de sus prácticas. Por tal motivo, el tema de la debilidad o fortaleza del Estado se transforma en un problema social (Migdal, 2011). Sobre todo porque el orden social es resultado de los complejos lazos desarrollados entre las instituciones estatales y los grupos o sujetos sociales que negocian, interactúan y resisten para generar formas diversas de integración y control sistémico (Migdal, 2011: 33).

La integración sistémica se produce a través de las selecciones y formas organizacionales de tipo piramidal, cuya cúspide es el Estado. Es diferente la integración social, donde los grupos con sus iniciativas y prácticas reorganizan las instituciones estatales (Herrera Gómez y Castón Boyer, 2003). Desde un punto de vista sociológico, existen dos tipos de controles: el sistémico y el social (Herrera Gómez y Castón Boyer, 2003: 17). El control sistémico es ejercido por las instituciones estatales mediante las políticas públicas que promueven el bienestar -cuya normatividad se deriva de los derechos ciudadanos-y favorecen la estabilidad social. Sin embargo, el control sistémico estatal ha sufrido cambios en la medida en que se han replanteado las políticas públicas como consecuencia de los cambios sociales y económicos que impulsaron la universalización del modelo de organización política y económica, identificado con la democracia representativa y el libre mercado, sobre todo, a raíz del fin de los regímenes del socialismo real de Europa del Este y Central (Nikolic, 1995) ${ }^{1}$.

La creencia en el libre mercado, sostenida por la política económica neoliberal, provocó, hasta cierto punto, una 
Reflexiones sobre la violencia y vulnerabilidad en México

desregulación o desnormativización de la sociedad, generando así su fragmentación y pluralización, y favoreciendo la aparición de nuevos actores que plantearon problemas a la integración sistémica estatal en un momento en que se redefinía el rol regulativo del Estado (Bauman, 2008). La disminución de la capacidad de regulación del Estado, y en consecuencia de su posibilidad de integración sistémica a través de las políticas sociales, ha sido interpretada como la causa de la expansión de la vulnerabilidad social, es decir, de la multiplicación de la pobreza y la miseria que se han convertido en la base del sentimiento colectivo de incertidumbre y temor individual a formar parte de los desechables (Bauman, 2008: 18-20).

Los desechables, desde un punto de vista general, son los grupos sociales afectados por un proceso de empobrecimiento creado debido al fin de la sociedad organizada por el trabajo asalariado. El trabajo asalariado cumplió la función de integración sistémica por la existencia de un sistema de bienestar estatal -considerado como una materialización de los derechos sociales-y de integración social, porque un empleo estable y de larga duración creaba certeza sobre el futuro y, a su vez, la esperanza de que el mejoramiento socioeconómico sería una herencia para las familias de los trabajadores (Dubet, 2011). En ese escenario, la desigualdad social no quedaba abolida, pero se reproducía bajo el esquema de la redistribución de la riqueza, apoyada en las políticas sociales que reequilibraran el reparto de las fortunas, disminuyendo así las inequidades sociales y garantizando posiciones a los más débiles (Dubet, 2011: 21). El mercado capitalista fue considerado una fuente de inequidades que debían ser reguladas por el Estado; se favoreció el control de los conflictos sociales derivados de la relación capital-trabajo (Polanyi, 2003).

La vulnerabilidad social es consecuencia de la crisis de la sociedad del trabajo y de la debilidad de las protecciones 
sociales administradas o gestionadas por el Estado. En otras palabras, la capacidad de control sistémico de las inequidades por parte del Estado se ha reducido, y esta situación, según mi punto de vista, ha sido provocada por la redefinición de las fronteras sociales entre lo público y lo privado. Dicho de otro modo, la ideología neoliberal creó la imagen de que las nuevas funciones del Estado eran las de mantener el orden normativo que garantizaba la vida y las propiedades, mientras que las prácticas económicas y sociales deberían de crear sus propias reglas limitadas a su propio ámbito de acción (Migdal, 2011: 35).

No obstante, la vulnerabilidad social no debe considerarse como la causa directa del crecimiento de las tasas de criminalidad, sino, como el aumento de los supernumerarios o desechables que están obligados a la sobrevivencia y que, bajo ciertas circunstancias, pueden llegar a ser criminalizados por el Estado (Wacquant, 2000). Pero la criminalización de estos individuos no se debe a que el Estado haya abandonado su función social en pos de su función punitiva; se debe a que los individuos vulnerados son infractores del orden legal establecido (Castel, 2004). Así es como se descarta la existencia de una guerra contra los pobres puesta en marcha desde el Estado; lo que hay son cambios en las instituciones de castigo que buscan penalizar las nuevas prácticas sociales. Por tal motivo, el castigo es un hecho social que tiene su propia historia y que depende de las modificaciones sufridas en las creencias colectivas acerca de lo que debe castigarse y la manera en que las instituciones estatales las codifican y las llevan a la práctica (Garland, 2007). En consecuencia, la importancia que ha adquirido la función punitiva se debe a las transformaciones ocurridas en el Estado, las cuales, en algunos casos, son atribuidas a la crisis del Estado de bienestar (véase Jessop, 1999). Considero que lo anterior responde también a la necesidad de crear seguridad y orden público desde una perspectiva 
Reflexiones sobre la violencia y vulnerabilidad en México

conservadora de gobernar las incertidumbres surgidas de la crisis de la sociedad del trabajo, lo cual es independiente de las ideologías partidistas de derecha o izquierda (Garland, 2007: 30-1).

El gobernar las incertidumbres significa orientar el comportamiento social mediante reglas e influencias directas e indirectas ejercidas no solamente por el Estado sino por individuos y grupos sociales en diferentes contextos o situaciones (Trombadori, 2010: 131). Las incertidumbres han sido interpretadas como el fin de las certezas establecidas por el Estado de bienestar (Navarro, 2000), pero desde la posición de los integrados, es decir, de los privilegiados, las incertidumbres han sido interpretadas como riesgos y peligros de perder posiciones y beneficios, transformándose de ese modo en vulnerables. Aun así, el temor a convertirse en vulnerable no significa que se adopte una visión negativa de los que lo son ni que se apoyen las acciones punitivas contra los mismos (Cfr. Wacquant, 2005: 7-10).

La vulnerabilidad de los individuos y grupos puede deberse a problemas derivados de la debilidad del control sistémico y social. En las sociedades regidas por un Estado de bienestar se impedía que las desigualdades se multiplicaran y se evitaba que estas tuvieran otra causa que la mera diferencia de ingresos obtenidos por la condición de asalariado (Dubet, 2000). Por tal motivo, la vulnerabilidad multiplicada es un problema particular de la desigualdad social relacionada con aspectos diferentes a la relación capital-trabajo; factores tales como la cultura, la religión, la raza, el género. Este hecho se encubrió por la existencia del Estado de bienestar en las sociedades centrales; el mismo logró compaginar la igualdad formal democrática con las desigualdades capitalistas, sobre todo, las derivadas de la sociedad asalariada, donde el trabajo era el vínculo de la integración social, mientras la integración sistémica se alcanzaba mediante el Estado de bienestar (Dubet, 2000: 
15). Por lo visto se entiende que la crisis en las sociedades desarrolladas es sistémica y social, y que esto signifique que la igualdad formal de la modernidad democrática tiene problemas para su vigencia, porque las desigualdades capitalistas han dejado de ser procesadas por un sistema de protecciones y de derechos sociales que debía su existencia al susodicho Estado de bienestar.

Lo anterior muestra que en las sociedades capitalistas hay problemas para que exista un mecanismo que articule las normas y valores de sus integrantes con las condiciones sistémicas de funcionamiento a las que estos están sometidos. En otras palabras, no concuerdan las normas y reglas de comportamiento de los individuos, la integración social, con los imperativos funcionales y las leyes objetivas a las que está sometido el sistema (Offe, 1996: 49): es la razón de la ingobernabilidad que los regímenes neoconservadores han intentado resolver mediante la búsqueda de la autorregulación del mercado y a través del establecimiento de valores tradicionales que reivindican la ley y el orden.

Así las cosas, los problemas de gobernabilidad se explicarían por la falta de concordancia entre la integración social y la sistémica. Esto podría desembocar en conflictos que no fueran necesariamente criminalizados por el Estado. A pesar de las perspectivas desarrolladas, no queda clara la razón estatal de criminalizar las acciones particulares de determinados grupos; no niego que esa determinación termina por justificar la existencia institucional del castigo; tampoco niego la reorganización sistémica emprendida por los gobernantes para controlar la criminalidad, dado el creciente temor individual originado por la percepción social del aumento de actividades criminales (Davis, 2006).

Los conceptos vulnerabilidad e integración social y sistémica fueron elaborados para explicar la crisis de la sociedad del trabajo y del Estado de bienestar, e incluso, para establecer, en algunos casos, las razones de la criminalización 
Reflexiones sobre la violencia y vulnerabilidad en México

de la pobreza y la miseria. Sin embargo, ambos resultan insuficientes para la elaboración de argumentos que ayuden a comprender la presencia de un marco de excepción en los países democráticos centrales, los cuales han conjuntado esfuerzos en una guerra global contra el terrorismo después de los atentados del 11 de septiembre de 2001 en EEUU (Mattelart, 2009); evento que ha tenido como consecuencia el uso creciente de dispositivos de vigilancia en la vida cotidiana de los ciudadanos, vinculando la seguridad con el uso de la tecnología e identificando la gestión de la seguridad del riesgo con un problema técnico que atenta contra las libertades y derechos de los individuos que viven en una sociedad democrática (Mattelart, 2009: 11-3).

De este modo, se identificó el riesgo y el peligro en los terroristas de origen árabe; se transformó la seguridad en un paradigma ${ }^{2}$ para gestionar el desorden, no para impedirlo, sino, para controlarlo y mantenerlo bajo determinados límites (Agamben, 2008: 108). El marco o estado de excepción se caracteriza por su ambigüedad, porque se presenta como la forma legal de aquello que no puede tener forma legal; además de relacionarse con la guerra civil y la insurrección, porque ambos son eventos extremos ante los cuales el poder estatal responde. Por eso, la instauración de un estado de excepción moderno es una guerra civil legal que permite la eliminación física de los adversarios políticos, y hasta de los ciudadanos que no son integrados por cualquier motivo en el sistema político (Agamben, 2007: 24-5).

Existe un proceso mediante el cual la excepción se convierte en regla cuando los individuos son despojados de sus derechos y libertades, e incluso de su identidad, para ser definidos como enemigos que deben ser combatidos y, en consecuencia, quienes atenten contra su vida no sufrirán

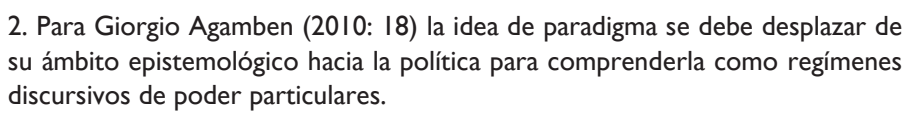


castigo alguno, puesto que la vida se ha vuelto parte de la política que está organizada de acuerdo con sus exigencias (Agamben, 2006: 18-23). ${ }^{3}$

Por otra parte, el riesgo se autonomiza del peligro cuando los dispositivos o artefactos tecnológicos se utilizan para formar bases de datos sobre la vida y las formas de vivir de varios individuos que tienen como objetivo disminuir la probabilidad de ocurrencia de comportamientos indeseables, volviéndose parte de las políticas preventivas que han promovido un nuevo modo de vigilancia practicado y sin contacto personal (Castel, 1991: 287-8). La existencia de un estado de excepción no excluye el uso de la tecnología de la vigilancia y control; sobre todo porque invalida la vieja idea de que los actos delictivos son generados por la debilidad o ruptura del lazo del individuo con la sociedad (Downes y Rock, 2011: 330). De hecho, el individuo rompe con la sociedad solo en una situación extrema, cuando se ha convertido en un desafiliado, y esto depende de un proceso que lo ha desplazado de la esfera de la inserción (donde era un asalariado y gozaba de los beneficios del sistema de bienestar estatal) hasta la vulnerabilidad, caracterizada por la incertidumbre laboral, donde las protecciones estatales son mínimas. Cuando el individuo se transforma en un desafiliado es porque se encuentra en una situación de desempleo sin derechos sociales. Es en esa situación donde se presenta una ruptura con la sociedad (Castel, 1995).

Desde una visión sociológica, en contraste, el paso de la sociedad disciplinaria a la sociedad de control es resultado

\footnotetext{
3. Por supuesto, lo anterior no tiene relación con el riesgo y el peligro derivado de una acción violenta impredecible a manos de una persona mentalmente inestable. Una acción de esta naturaleza sería calificada de patológica y en ese caso el crimen sería obra de un lunático. En consecuencia, la manera de prevenirlo sería mediante tecnologías de confinamiento y esterilización (Castel, I99I: 283-4). Sin embargo, se debe de destacar que desde el poder se han desarrollado tecnologías de control y prevención de las conductas, lo que forma parte de un programa de intervención política con especialistas como los trabajadores sociales y los siquiatras.
}

\section{6}


Reflexiones sobre la violencia y vulnerabilidad en México

del abandono de la visión individualizada basada en la disciplina practicada en instituciones particulares como la escuela, el hospital, la fábrica, la cárcel, etcétera, sobre los cuerpos mediante las técnicas de vigilancia para adquirir un carácter masivo que se aplica a la población desde el poder soberano que decide sobre su vida y muerte (Gallardo Cabrera, 2011: 50-1). Esto último ha sido posible por el biopoder, es decir, por una bioregulación gestionada por el Estado, lo que ha desembocado en la aparición de la sociedad del control (Foucault, 2007). Gobernar es la organización de acciones que buscan conducir conductas mediante mecanismos de control y de regulación que se han vuelto parte de las instituciones estatales al gubernamentalizarse (Gallardo Cabrera, 2011: 55). El desarrollo de las tecnologías y las comunicaciones para el control de las poblaciones se consolidó y, al mismo tiempo, se individualizaron los riesgos, los cuales perdieron su carácter colectivo o social cuando el proyecto neoliberal se erigió como sustituto de una gestión realizada por el Estado de bienestar. Así, el riesgo se pude entender como una inseguridad provocada por la ausencia de planes de pensión y de salud, y de empleo remunerado, lo que ha fortalecido la creencia de que una situación de seguridad solo se puede alcanzar por alarmas, cámaras de videovigilancia, dispositivos de identificación que se podrían adquirir en el mercado de bienes de seguridad (Rodríguez Fernández, 2010).

En efecto, la seguridad personal está en la participación de actividades para la acumulación de datos individuales que están al servicio del control, como los viajes de avión, las tarjetas de crédito y débito, la telefonía móvil, y el uso de Internet. Todas son actividades que se controlan mediante la acumulación de datos personales y sin tocar el cuerpo. Este acontecimiento ha sido usado por las instituciones estatales para considerar a los grupos de riesgo a partir de la existencia de una base de indicadores estadísticos 
sobre los mismos, y que sirve para controlarlos cuando han superado el promedio o parámetro que se contempla como límite (Rodríguez Fernández, 2010: 43-4).

\section{Vulnerabilidad y violencia}

La existencia de un estado de excepción al margen de los derechos ciudadanos es lo que en realidad genera vulnerabilidad para los que son considerados los desechos de una modernidad líquida que, desde un punto de vista general, se caracteriza por la generalización de la incertidumbre en la vida cotidiana, provocada por la existencia de una precariedad laboral y de ingresos ${ }^{4}$ reflejada en una ampliación de la desigualdad social (Díaz-Salazar, 2011).

La vulnerabilidad social, al ser resultado de una pérdida de los derechos ciudadanos y de las condiciones materiales para su realización por parte de los individuos, se puede interpretar como una ausencia de soportes identitarios, los cuales, en otras palabras, son lo que mantiene a los individuos en una situación de inclusión, gracias a la existencia de un sistema de regulación y protección, que se había edificado sobre el trabajo asalariado (Castel, 2010).

La pérdida de los soportes materiales para la realización de la individualidad en sociedad crea una exposición mayor a los riesgos del sistema capitalista, como el desempleo y la enfermedad; sin embargo, este hecho puede ser conside-

4. El paso de la fase sólida a la líquida de la modernidad significa que las instituciones que daban continuidad a los hábitos ya no mantienen su forma más tiempo; mientras que el poder se ha desplazado, o al menos parte del mismo, hacia un espacio global. Provocando que los poderes emancipados no sufran control político alguno porque el Estado ha delegado un gran número de funciones; al mismo tiempo, se han reducido los seguros públicos, garantizados por el Estado y que cubrían el fracaso o la mala fortuna individual. Una vida fragmentada ha significado el fin de la planificación y de la acción a largo plazo. Finalmente, sobre los individuos recae la responsabilidad de los efectos derivados de las circunstancias volátiles. En sus elecciones existen riesgos originados por fuerzas que trascienden su comprensión y capacidad individual (Bauman, 2007: 7-12). 
Reflexiones sobre la violencia y vulnerabilidad en México

rado como violencia estructural o sistémica: la que produce la dinámica capitalista, y que es vivida como una pérdida individual de reconocimiento social por ser un desafiliado o un vulnerable (Castel, 2010: 23-4). Por otro lado, pueden existir actos de violencia entre grupos sociales debidos a conflictos de reconocimiento que se relacionan con la identidad y con el no goce de los derechos ciudadanos (véase Honneth, 1997). Esto último también es resultado del acaparamiento de oportunidades por los grupos privilegiados, lo cual opera a favor de la reproducción de la desigualdad social (Tilly, 2007: 10).

Pese a ello, la violencia ejercida por el poder político o soberano ${ }^{5}$ contra la vida humana ${ }^{6}$ es el resultado de la destrucción de una identidad social particular que ya no encuentra soportes materiales en la sociedad y torna precaria la vida de los afectados (Butler, 2006: 60-1). La existencia de un estado de excepción justifica el uso de la violencia contra la vida de los que han sido definidos como enemigos; enfáticamente en los que previamente han sido despojados de sus derechos ciudadanos. Aun así, la multiplicación de las vulnerabilidades sociales es resultado de los cambios introducidos en el Estado de bienestar y en la economía capitalista de servicios, que, basada en el conocimiento tecnológico, ha afectado de manera directa el mundo del trabajo (véase Cohen, 2001).

Por consiguiente, el concepto de vulnerabilidad social ha sido utilizado para explicar el castigo hacia los pobres desprotegidos por las instituciones estatales de bienestar y en paro; situación que se puede convertir en una causa para delinquir y poder sobrevivir (Wacquant, 2007), y tiene su

5. El poder político es soberano porque al mismo tiempo esta fuera y dentro del ordenamiento jurídico. Sobre todo, porque el ordenamiento jurídico vigente le reconoce el poder de proclamar el estado de excepción (Agamben, 2006: 27). 6. La vida humana es una nuda vida porque un individuo llega a ser ciudadano cuando la pone a disposición del poder político (Agamben, 2007: 7). 
manifestación territorial en barrios 'prohibidos', 'zonas de no derecho', caracterizadas por la privación y el abandono, donde 'reina' el vicio, la violencia y la disolución social (Wacquant, 2007: 13-9).

Desde este punto de vista, el acaparamiento creciente de las ventajas en un pequeño grupo de privilegiados tiene su contraparte en el aumento de los pobres y desempleados. $\mathrm{Y}$ esto mismo refuerza el sentimiento de inseguridad de los primeros ante la exposición a un posible 'atentado' de los segundos contra sus vidas y propiedades, lo cual hace posible la existencia de un control social o de colonos que aprovecha las tecnologías de vigilancia y registra lo que acontece dentro del aislamiento residencial donde los privilegiados se avecinan (Davis, 2003). En realidad se trata de una violencia sistémica, cuyo resultado son algunas consecuencias negativas derivadas del sistema económico y político organizado a través del modelo de la democracia liberal y de libre mercado, pero este tipo de violencia es gestionada por medio de la política del miedo que busca controlar los desordenes derivados de la violencia sistémica (Zizek, 2009).

El amurallado es acompañado por la percepción colectiva del riesgo que representan los individuos estigmatizados por la pobreza y la miseria, confinados en un territorio especial; esta misma contribuye a afianzar la creencia de que los individuos que ahí habitan son un peligro potencial para los que gozan de prerrogativas. Así es que se favorece el surgimiento de una violencia subjetiva, la cual puede tener como sustento los fundamentalismos éticos, racistas o religiosos (Zizek, 2009: 21-5).

Los temores y miedos colectivos han dado lugar a la aparición de una regulación de la seguridad y del bienestar de las vidas humanas, que se ha convertido en un problema de administración para los expertos que no reivindican ninguna ideología en particular, sino que orientan sus 
Reflexiones sobre la violencia y vulnerabilidad en México

acciones por la creencia en la eficiencia lograda a través de una administración especializada (Palidda, 2010). Por tal motivo, el castigo es visto como un instrumento tecnológico que es evaluado mediante su eficacia en el control de las tasas de criminalidad.

El control de las tasas de criminalidad ya no depende solo de la disciplina apoyada por los especialistas; ahora depende de nuevas racionalidades burocráticas o administrativas, que se caracterizan por el advenimiento de la excepcionalidad penal para no tolerar al enemigo definido por el derecho. En otras palabras, la acción punitiva estatal está guiada por la consigna tolerancia cero para el enemigo. En virtud de lo anterior se explica que el terrorismo y los traficantes de drogas junto con las migraciones masivas irregulares sean parte de las proclamas que justifican la acción punitiva estatal y que se presentan como necesarias por ser parte de la 'nueva' guerra. Estas consideraciones conducen a establecer que cuando el Estado proclama la excepcionalidad justifica sus crímenes y, en algunos casos, sus genocidios, causando así una victimización importante (Rivera Beiras, 2010: 84-6).

La excepcionalidad penal, desde el punto de vista analizado, es una manifestación particular de la violencia estructural, que es distinta de la que proviene del sistema económico capitalista, la cual ha sido resultado de la flexibilización laboral y de la crisis del Estado de bienestar. Así y todo, la excepcionalidad penal no descarta la violencia directa o física, porque la criminalización del enemigo implica su exterminio a través del uso de la fuerza del ejército y de las organizaciones policíacas especializadas. Tampoco deja de lado el castigo contra los enemigos mediante su confinamiento y encierro; una medida que descarta su posible reintegración social, dada la consideración de los expresidiarios como peligro para la sociedad, y de sus acciones como delitos de alto impacto social. 
La excepcionalidad penal puede, de manera indirecta, favorecer la multiplicación de situaciones de violencia (Collins, 2008). Sin embargo, esto no significa que exista una relación de causa-efecto ni que su carácter punitivo genere la aparición de enfrentamientos o confrontaciones armadas entre diferentes grupos. Las confrontaciones violentas, desde una perspectiva microsociológica, dependen más de la interacción; lo que significa que el individuo no es la principal entidad en el análisis, sino sus motivaciones, relacionadas con la cultura y con los principios organizativos de una sociedad.

Pero como las situaciones de violencia son diferentes: existen diversos tipos de violencia; no hay violencia individual, sino situaciones de violencia, puesto que los contornos de las situaciones configuran los actos y emociones de los individuos involucrados en actos de confrontación o violencia. A causa de ello, la violencia no puede ser explicada por variables aisladas, tales como la pobreza, la raza, la juventud, la niñez desamparada y la ilegalidad, dado que estas permiten que surja una situación de nula interacción que puede traducirse en tensión y confrontación (Collins, 2008: 2). Las situaciones de violencia en la vida cotidiana son pequeñas o limitadas: no cubren todo el espectro. Quiere decir que los actos de violencia solamente se presentan en ciertos momentos y en situaciones muy particulares. Por tal motivo, el enfoque individual de la violencia física se limita a una descripción cuantitativa de las características demográficas de los criminales; descartándose explicaciones que tengan un fundamento social (Muchembled, 2010).

Sin entrar en particularidades, la violencia que se manifiesta a través de las guerras contemporáneas involucra a los Estados. Al poder soberano que ha hecho de la excepción una regla para criminalizar y castigar a los que considera sus enemigos. La violencia es una construcción social que, desde una perspectiva histórica, ha sufrido cambios o trans- 
Reflexiones sobre la violencia y vulnerabilidad en México

formaciones, y que pese a ellos mantiene una constante: el castigo; un ritual organizado la autoridad estatal de manera emocional y simbólica (Muchembled, 2010: 31). La violencia también se ha acompañado de diversas formas de control que buscan frenar actos que se consideren un riesgo para el orden social. Por tal motivo, dichas formas son un asunto cultural (Garland, 2001).

Los cambios que se presentaron en la cultura del control del delito y de la justicia penal son producto del advenimiento de la modernidad tardía a la cual dio forma el modelo económico neoliberal y el neoconservadurismo de los gobiernos de los Estados Unidos y de la Gran Bretaña, a partir de los años ochenta del siglo XX (Garland, 2001: 3-14). No obstante, insisto no se pude ver una relación causal entre el ascenso del neoliberalismo económico y el neoconservadurismo gubernamental para explicar el cambio en la cultura del control del delito. Sobre todo, porque la relación entre estos cambios sistémicos y la actividad delictiva no es unívoca, y porque no se puede considerar el sistema penal como independiente del sistema económico y social.

El establecimiento del estado de excepción es una decisión gubernamental que crea una violencia estructural particular, ${ }^{7}$ la cual, no cabe duda, se manifiesta como violencia física contra los individuos o grupos que han sido considerados como enemigos o criminales (Correas, 2011).

En la otra cara de la moneda se observa que la vulnerabilidad social es resultado de las transformaciones o cambios ocurridos en la sociedad organizada por el trabajo asalariado, y sin embargo, la aparición de una nueva cultura del control del delito es producto tanto de los cambios económicos y de valores y creencias relacionadas con el

7. Esto significa que la presencia del Estado es parcial o no existe porque no puede garantizar la seguridad ni el bienestar social debido a que sus instituciones realizan su s tareas de gestión o administración de manera deficiente (Maldonado, 2010: 23).

Sociedad $\&$ No.61 
neoconservadurismo político como también del establecimiento de un estado de excepción que le permite al poder político declarar enemigos y criminalizar a ciertos grupos.

Conviene en este punto destacar que el poder político o soberano tiene a su disposición la vida de los criminalizados y puede ejercer violencia física contra ellos. En tanto, la excepcionalidad se convierte en una regla no escrita que tiende a desplazar las reglas escritas; a pesar de que luego haya una voluntad de legalización gracias a que el soberano ${ }^{8}$ es parte y no del orden jurídico, sobre todo porque existe la facultad de desconocerlo al declarar el estado de excepción (Agamben, 2006: 28-9).

\section{El estado de excepción mexicano}

El México de la transición democrática, grosso modo, se caracterizó por la alternancia partidista en los diferentes puestos de ejercicio del poder local y regional, lo cual culminó en el año 2000 con un cambio partidista en la presidencia del país que significó el fin de la hegemonía de un partido. Esto significó también el fin de un mecanismo institucional de acceso al poder y a los diferentes puestos de gobierno, y la consolidación de un sistema hegemónico de partidos (Aziz Nassif, 2009: 9). Este sistema de partidos ha permitido que las responsabilidades de gobierno sean

8.“ [...] Foucault distinguió el poder que se desarrolló a partir del siglo XVIII del concepto tradicional de soberanía, llamándolo poder sobre la vida o biopoder [...] dejó de ejercerse esa pura relación de sometimiento que permitía al soberano sustraer bienes, apropiarse de riquezas, apoderarse del cuerpo o de la vida del súbdito, y cuando, en cambio, el poder comenzó a actuar sobre los individuos como miembros de una especie biológica que es tomada en consideración en tanto se la quiere utilizar para producir riquezas, bienes o incluso otros individuos; es decir, cuando sale a la luz la noción de población, como principio económicopolítico fundamental, o máquina regulable a través de las tasas estadísticas, observable en las tablas demográficas, gobernable a través de la gestión de las condiciones de vida (hábitat, ciudad, higiene, seguridad en el sentido amplio del término), de sus flujos, el control de los nacimientos y las migraciones" (Cavalletti, 2010: 17).

\section{4}


Reflexiones sobre la violencia y vulnerabilidad en México

compartidas, pero ha reproducido una ciudadanía precaria o débil y con derechos limitados o inexistentes (Aziz Nassif, 2009: 11). A pesar de ello, México tiene un régimen político con una democracia representativa y un sistema político con una inercia autoritaria. En otras palabras, el acceso al poder esta garantizado a través de la celebración de elecciones, y no obstante, las prácticas y los intereses políticos siguen desdeñando el orden legal y mostrando su impunidad y autoritarismo. El orden derivado del sistema político está más relacionado con el poder que ejerce la élite política pluralizada que con el orden legal: las normas y leyes escritas (Duhau y Giglia, 2008: 13).

La alternancia fortaleció los gobiernos municipales y estatales, pero no cambió las atribuciones de los poderes e instituciones del sistema político, que continuaron con el mismo funcionamiento institucional, salvo que los poderes locales y estatales se liberaron de los controles informales ejercidos por la presidencia autoritaria de un partido hegemónico, como lo fue el Partido Revolucionario Institucional (PRI). Por tal motivo, las facultades jurídicas institucionales son aplicadas por los partidos políticos en el Congreso de la Unión, y estas se orientan por los intereses particulares de cada uno de ellos (Hernández Rodríguez, 2008: 15). Este acontecimiento ha mostrado a un presidente débil y sin facultades para controlar los excesos, por ejemplo, de los gobernadores. La autonomía de los gobernadores les ha permitido disponer de manera discrecional de los recursos presupuestales sin importar sus montos. A su vez, han fortalecido a los poderes locales de tipo caciquil que no tienen obstáculos para cometer arbitrariedades que no son del todo castigadas (Hernández Rodríguez, 2008: 16-7).

Entonces, las prácticas informales que emanan del sistema político, insisto, se reflejan en el ejercicio del poder político, cuya alternancia ha dado más poder a los gobernadores y ha disminuido el que se ejerce desde la presidencia 
del país. Así, el ejecutivo federal debe negociar con los otros poderes para establecer sus iniciativas, aunque la presidencia de la alternancia emanada del Partido Acción Nacional (PAN) no lo logró del todo y tuvo que usar sus facultades discrecionales para realizarlo. ${ }^{9}$ Esta situación ha reproducido los rasgos personales de la presidencia, tal como sucedía en el largo periodo en que la presidencia de México estuvo en manos del PRI, y el jefe del poder ejecutivo tenía una autoridad tal que se imponía a las instituciones con una aplicación arbitraria de la ley. Este personalismo autoritario se mantuvo precisamente para evitar los obstáculos administrativos y legales, y para conservar una imagen presidencial positiva ante la opinión pública. Fue un estilo vinculado con las circunstancias personales del presidente. Así sucedió durante la administración del panista Vicente Fox (2000-2006); su proyecto de gobierno se construyó sobre el autoritarismo derivado de la personalidad del presidente (Loaeza, 2010: 243-275). Luego, en las elecciones presidenciales del 2006, el PAN obtuvo nuevamente el poder con Felipe Calderón Hinojosa; se consolidó una identidad de derecha entre el electorado, sin importar su condición socioeconómica, y aun a pesar de que la estrategia de la izquierda partidista se haya basado en una ideología de oposición entre ricos y pobres, y de que se haya creído, junto con el candidato de la izquierda (Andrés Manuel López Obrador), que dado que el número de pobres es mayor que el número de ricos, los primeros votarían en su favor y la izquierda ganaría las elecciones (Loaeza, 2010: 279-81).

Se puede observar que el poder político mexicano se ejerce de manera informal y reproduce diversas situaciones de 
Reflexiones sobre la violencia y vulnerabilidad en México

excepción que resultan favorables a la existencia de una democracia participativa débil (Aziz Nassif y Alonso, 2009). El estado de excepción mexicano es una situación permanente que protege los intereses de los sectores dominantes y que no favorece a los vulnerables; además, provoca que no exista un carácter universal de los derechos ciudadanos, lo que reproduce una ciudadanía precaria, caracterizada por derechos y obligaciones no realizables, con un claro predominio de la ilegalidad (Durand Ponte, 2010: 34-5).

Considero que si el sistema político mexicano conserva las inercias autoritarias, a pesar de la alternancia partidista, el estado de excepción se vuelve permanente (véase Delich, 2007) y, en consecuencia, no debe de resultar extraño que desde el poder presidencial panista se criminalice el narcotráfico y se ejerza contra el mismo la fuerza pública al margen del orden legal.

La decisión personal del presidente Felipe Calderón de combatir a los cárteles de la droga no se puede considerar un mero capricho individual: fue posible porque existe un estado de excepción. Un estado de excepción que en la coyuntura electoral de 2006 se ha pensado que influyó para que el presidente Calderón, desde el inicio de su administración, usara el combate al narcotráfico como estrategia política (Enrique Osorno, 2009: 45). Esta aseveración cobra fuerza debido a que en diversos actos públicos el entonces presidente habló de una "guerra contra el narco". Al mismo tiempo, definió como enemigos de la seguridad nacional a las diferentes organizaciones de narcotraficantes, individualizando también la acción punitiva contra sus líderes y suponiendo que el problema se irá resolviendo con la detención de estos. La acción punitiva de Felipe Calderón contra el narcotráfico respondió también a la existencia de una politización creciente del combate a las drogas por parte de los diferentes gobiernos de los Estados Unidos en sus intentos por establecer un régimen transnacional de 
prohibición; intentos datados desde la década de los setenta del siglo XX (Enciso, 2009: 183).

Por otro lado, el estado de excepción favoreció en algunas regiones del país una situación en la cual las autoridades de distintos niveles gestionaron de manera deficiente los asuntos públicos, y esto permitió la proliferación de actividades ilegales e informales, como el narcotráfico u otras, como lo sucedido en ciudad Juárez (Herrera Robles, 2010: 24-5). El uso político del combate contra el narcotráfico se puede entender desde otro ángulo: como un intento presidencial por poner límites a las complicidades desarrolladas entre los jefes de negocios ilícitos y determinados funcionarios públicos, policías y miembros del ejército (Ravelo, 2011). Algunas de las consecuencias de esta guerra presidencial contra el narcotráfico se pueden ver en la proliferación de territorios del terror, caracterizados por una alto nivel de violencia física, y el consecuente temor y sentimiento de inseguridad generalizado entre sus habitantes, no sin fundamento: muerte de civiles e incluso despoblamiento de localidades enteras en el norte de México (Gregory y Pred, 2007; Turati, 2011). En los territorios del terror la violencia es evidente en los enfrentamientos armados con las organizaciones del narcotráfico, y estos validan, según mi punto de vista, la idea de la existencia de situaciones de violencia, corroboradas, hasta cierto punto, por el número de homicidios. ${ }^{10}$

Por otro lado, la acción punitiva presidencial se basó en una profesionalización de los cuerpos policíacos, que, junto con penas más severas para los enemigos de la "salud

10.“Entre 1992 y 2007 disminuyeron sistemáticamente, año con año, tanto la tasa nacional como el número de homicidios. La tasa pasó de un máximo de 19.72 en 1992 a un mínimo de 8.04 en 2007[... sin embargo], el número de homicidios [...] aumenta muy significativamente el peso proporcional en el número de víctimas de los estados de la frontera norte [en particular; Baja California, Sonora, Chihuahua y Tamaulipas] y disminuye el peso de los estados del centro y sur del país [sobre todo del Estado de México, Oaxaca y Guerrero]" (Escalante Gonzalbo, 2009: 1 17-8). 
Reflexiones sobre la violencia y vulnerabilidad en México

pública”, suponían una medida preventiva que evitaría la "infiltración" de las actividades del narco en los agentes de policía locales y estatales. Pero esta medida solo manifiesta la introducción de cambios en la regulación y control estatal de las conductas delictivas, que en una situación de excepción, significa legitimar el combate contra los individuos y grupos que han sido identificados como enemigos y que es necesario confinar o destruir (véase Azaola Garrido y Ruiz Torres, 2009: 37).

El estado de excepción posibilitó que el régimen político de partido hegemónico tolerara las actividades del narcotráfico por ser un negocio redituable para una parte de la élite política, o lo que es lo mismo: hubo tolerancia oficial, complicidad. Es así que en la década de los setenta del siglo pasado el ejército combatió de manera frontal a los grupos subversivos, pero no con la misma intensidad a los narcotraficantes (Flores Pérez, 2009: 175-6). Tal situación es otra evidencia de que el poder político ha utilizado la excepcionalidad para castigar a los que considera que son sus enemigos y justificar su exterminio. Durante los años sesenta y setenta del siglo XX, las instituciones de seguridad estatal ejercieron el control político y social de la oposición social y de la disidencia armada, desde donde se prestaron servicios de protección a la delincuencia, como lo fue la Dirección Federal de Seguridad, entidad que funcionó como policía política del régimen del PRI (véase Torres, 2008).

La impunidad de los encargados del control social permitió no solo la arbitrariedad, sino la corrupción favorable al desarrollo de ligas con los negocios de los narcotraficantes. Con todo, los representantes del Estado mantuvieron el control de las actividades ilícitas. En los ochenta, cambió la situación, debido a que la demanda de narcóticos en los Estados Unidos aumentó. Mientras los narcotraficantes se dispersaron en el territorio nacional por la Operación Cóndor, se abrieron nuevas rutas de tráfico de cocaína en 
México por las acciones punitivas estadounidenses realizadas en el mar Caribe; mismas que produjeron altas ganancias para los funcionarios de las instituciones de seguridad nacional (Flores Pérez, 2009: 181-5).

El Estado garantizó la reproducción del negocio ilegal del tráfico de drogas, en un primer momento, mediante la Dirección Federal de Seguridad, después, con su desaparición, mediante la Procuraduría General de la República. Desde un punto de vista general, el resquebrajamiento de la protección central que se produjo a lo largo de la década de los noventa por las detenciones de altos funcionarios públicos sorprendidos en colusión con el narcotráfico generó que los narcotraficantes buscaran el amparo de las autoridades locales, es decir, una protección focalizada donde ya no existían reglas informales de operación generalizada. El control centralizado se debilitó y los líderes de las organizaciones del narcotráfico se volvieron más autónomos, lo cual, de manera indirecta, fue un reflejo de las transformaciones que sucedieron a nivel del sistema político, afectado por la alternancia partidista.

Tal como se ha destacado, el estado de excepción no ha desaparecido; es más, se ha utilizado para definir enemigos en un intento por rehacer los controles estatales de la criminalidad, utilizándose la tecnología de vigilancia y modificándose leyes para ampliar los años de encierro; también, creándose mecanismos de investigación y vigilancia que incluyen la profesionalización de los cuerpos armados. Sin elaborar una evaluación de estas medidas, se intenta establecer un nuevo modelo de seguridad, uno orientado por la idea de eficiencia en el combate contra el crimen organizado. Así las cosas, el carácter punitivo del estado de excepción no es abandonado ni se busca terminar con él. Finalmente, se sigue reproduciendo la ciudadanía precaria al buscar que la población participe en el combate y en la prevención del delito (García Luna, 2011: 24). 
Reflexiones sobre la violencia y vulnerabilidad en México

\section{Reflexión final}

El concepto vulnerabilidad social ha sido elaborado para explicar el paulatino debilitamiento de las protecciones estatales de bienestar ante el aumento de los contingentes de desempleados o desechables de una economía organizada por un modelo flexible de producción, la cual anunció el fin del empleo fijo o de larga duración, disolviendo así las certezas sobre el futuro y dando paso a un periodo de incertidumbre que, de manera coyuntural, ha favorecido la expansión del miedo colectivo frente a la amenaza de la desafiliación. El individuo ya no tiene un lugar seguro en la sociedad y, por lo tanto, padece toda clase de penuria. Este hecho se puede interpretar como condición favorable para la reproducción de una ciudadanía débil o precaria.

A pesar de lo anterior, el temor al desempleo o subempleo -que conduce a la pobreza y a la miseria- ha sido interpretado, desde una posición neoconservadora de gobierno, como un problema individual. Por tal motivo, el bienestar ya no es un asunto exclusivo de las políticas sociales, sino, que depende más de las capacidades personales. Vulnerabilidad también significa ciudadanía débil y temor a sufrir los inconvenientes derivados de la marcha económica capitalista, tales como el desempleo y la enfermedad. Pero al conferirle a la vulnerabilidad la causa del aumento de las actividades ilícitas en una sociedad, se cae en la vieja creencia de que la pobreza y la miseria conducen a la criminalidad. Y ante la pérdida del carácter universal de la política social, se resalta la sustitución de la función social del Estado por su función punitiva. En otras palabras, el Estado castiga a los pobres que han perdido su funcionalidad económica y que para sobrevivir recurren a la ilegalidad. De esta manera, surge el Estado de la seguridad pública, el cual atiende los reclamos de protección de las propiedades y la vida de sus poseedores y usa su poder punitivo contra los desposeídos 
o excluidos del nuevo modelo económico. El concepto vulnerabilidad social tendría utilidad si se considerara como una manifestación de la violencia sistémica, es decir, la generada por el orden económico, social y político; a su vez, se comprendería que los cambios presentados en los diferentes sistemas sean una respuesta a la necesidad de rehacer sus dispositivos de control.

La criminalidad no es un asunto reductible a una situación de pobreza y se puede entender mejor si se visualiza como parte de las situaciones de violencia. El concepto estado de excepción ayuda a analizar las situaciones de violencia cuando el poder político construye enemigos, que, por considerarse un peligro para la paz pública, pueden ser ultimados ejerciendo la violencia directa.

En México, el estado de excepción no desapareció con la alternancia partidista garantizada por el régimen político, porque el sistema político, a través de los diferentes partidos políticos, reproduce el autoritarismo, la impunidad y la discrecionalidad; prácticas ajenas a las normas o reglas derivadas de un orden legal. En México existe una situación de ilegalidad permanente que tampoco ha sido 'borrada' por la alternancia presidencial del año 2000. El estado de excepción favoreció el desarrollo de los lazos entre el personal estatal y los negocios ilícitos del narcotráfico; primeramente mantenidos por el controlo desde las instituciones de seguridad durante el régimen de partido hegemónico, y luego por los poderes locales, cuando estos se agenciaron autonomía con el debilitamiento del presidencialismo mexicano. La respuesta desde el poder presidencial panista ante esa situación fue la criminalización, con la cual justificó el empleo del ejército para disponer de la vida de los que han sido ahora definidos como enemigos que atentan contra la seguridad nacional.

Fecha de recepción: 04 de diciembre de 2013

Fecha de aceptación: 14 de julio de 2014

\section{2}


Reflexiones sobre la violencia y vulnerabilidad en México

Agamben, Giorgio, 2006, Homo Sacer. El poder soberano y la nuda vida, Pre-Textos, Valencia.

__, 2007, Estado de excepción, Adriana Hidalgo, Buenos Aires.

__ 2008, "Comentarios de Giorgio Agamben y debate final”, en Zygmunt Bauman, Archipiélago de excepciones. Comentarios de Giorgio Agamben y debate final, Katz Editores/Centro de Cultura Contemporánea de Barcelona, Barcelona.

__, 2010, Signatura rerum. Sobre el método, Anagrama, Barcelona.

Azaola Garrido, Elena y Miquel Ángel Ruiz Torres, 2009, Investigadores de papel. Poder y derechos humanos entre la Policía Judicial de la Ciudad de México, Fontamara, México.

Aziz Nassif, Alberto, 2009, "El desencanto de una democracia incipiente. México después de la transición”, en Octavio Rodríguez Araujo (coord.), México ¿Un nuevo régimen político?, Siglo XXI, México.

Aziz Nassif, Alberto y Jorge Alonso, 2009, México. Una democracia vulnerada, CIESAS/Miguel Ángel Porrúa, México.

Bauman, Zygmunt, 2008, Archipiélago de excepciones. Comentarios de Giorgio Agamben y debate final, Katz Editores/ Centro de Cultura Contemporánea de Barcelona, Barcelona.

__, 2007, Tiempos líquidos. Vivir en una época de incertidumbre, Tusquets Editores, Barcelona.

Butler, Judith, 2006, Vida precaria. El poder del duelo y la violencia, Paidós, Buenos Aires.

Caldeira, Teresa, 20I0, Espacio, segregación y arte urbano en el Brasil, Katz, Buenos Aires.

Castel, Robert, 199I, "From dangerousness to risk", en Graham Burchell, Colin Gordon y Peter Miller (eds.), The Foucault Effect. Studies in Governmentality with two lectures by and interview with Michel Foucault, The University of Chicago Press, Chicago. 
Miguel Ángel Vite Pérez

Bibliografía $\quad$ - 1995, "De la exclusión como estado a la vulnerabilidad como proceso", Archipiélago, núm. 21, pp. 27-36.

_ _ 2004, La inseguridad social ¿Qué es estar protegidol?, Manantial, Buenos Aires.

__ 2010, Las transformaciones del trabajo, de la producción social y de los riesgos en un período de incertidumbre, Siglo XXI, Buenos Aires.

Castel, Robert y Claudine Haroche, 2003, Propiedad privada, propiedad social, propiedad de sí mismo. Conversaciones sobre la construcción del individuo moderno, HomoSapiens Ediciones, Rosario.

Cavalletti, Andrea, 20 I0, Mitología de la seguridad. La ciudad biopolítica, Adriana Hidalgo, Buenos Aires.

Cohen, Daniel, 200I, Nuestros tiempos modernos. "Un análisis del capitalismo y sus tendencias: ¿estamos ante el final del trabajo?", Tusquets, Barcelona.

Collins, Randall, 2008, Violence. A Micro-sociological Theory, Princeton University Press, EEUU.

Correas, Oscar, 20I I, La criminalización de la protesta social en México, Universidad Nacional Autónoma de México/ Ediciones Coyoacán, México.

Davis, Mike, 2006, Ciudades muertas. Ecología, catástrofe y revuelta, Traficantes de sueños, Madrid.

__, 2004, Ciudad de cuarzo. Arqueología del futuro en los Ángeles, Lengua de trapo, España.

Delich, Francisco, 2007, Sociedades invisibles. La cultura de la ingobernabilidad en América Latina, Gedisa, Buenos Aires.

Díaz-Salazar, Rafael, 20 I I, Desigualdades internacionales justicia ya; Hacia un programa mundial de justicia global, Icaria, Barcelona.

Downes, David y Paul Rock, 20I I, Sociología de la desviación, Gedisa Editorial, Barcelona.

Dubet, Francois, 20II, Repensar la justicia social. Contra el mito de la igualdad de oportunidades, Siglo XXI, Buenos Aires. 
Reflexiones sobre la violencia y vulnerabilidad en México

Dubet, Francois, 2000, Les Inégalités Multipliées, Éditions de I'Aube, París.

Duhau, Emilio y Angela Giglia, 2008, Las reglas del desorden: Habitar la Metrópoli, UAMA/Siglo XXI, México.

Durand Ponte, Víctor Manuel, 2010, Desigualdad social y ciudadanía precaria ¿Estado de excepción permanente?, IIS-UNAM/Siglo XXI, México.

Enciso, Froylán, 2009, "Drogas, narcotráfico y política en México: Protocolo de hipocresía (1969-2000)”, en llán Bizberg y Lorenzo Meyer (coords.), Una Historia Contemporánea de México. Tomo 4 las políticas, El Colegio de México/Editorial Océano, México.

Escalante Gonzalbo, Fernando, 2009, El homicidio en México entre 1990 y 2007. Aproximación estadística, El Colegio de México/Secretaría de Seguridad Pública Federal, México.

Enrique Osorno, Diego, 2009, El Cártel de Sinaloa. Una historia del uso político del narco, Grijalbo, México.

Foucault, Michel, 2007, Nacimiento de la biopolítica, Fondo de Cultura Económica, Buenos Aires.

Flores Pérez, Carlos Antonio, 2009, El Estado en crisis: Crimen organizado y política. Desafios para la consolidación democrática, CIESAS, México.

Gallardo Cabrera, Salvador, 20 I I, La mudanza de los poderes. De la sociedad disciplinaria a la sociedad de control, ALDVS, México.

García Luna, Genaro, 20I I, Para entender el nuevo modelo de seguridad, Nostra Ediciones, México.

Gergen, Kenneth J., y Mary Gergen, 20I I, Reflexiones sobre la construcción social, Paidós, Madrid.

Gregory, Derek y Pred Allan, 2006, Violent Geographies. Fear, Terror and Political Violence, Routledge, Nueva York.

Garland, David, 200 I, La cultura del control. Crimen y orden social en la sociedad contemporánea, Gedisa, Barcelona. 
Miguel Ángel Vite Pérez

Bibliografía $\quad$ - 2007, Crimen y Castigo en la Modernidad Tardía, Siglo del Hombre Editores/Universidad de los Andes/Pontificia Universidad Javeriana/Instituto Pensar, Colombia.

Herrera Gómez, Manuel y Pedro Castón Boyer, 2003, Las políticas sociales en las sociedades complejas, Ariel, Barcelona.

Hernández Rodríguez, Rogelio, 2008, El centro dividido. La nueva autonomía de los gobernadores, El Colegio de México, México.

— 2010, Juárez: el desgobierno de la ciudad y la política del abandono, Universidad Autónoma de Ciudad Juárez, México.

Honneth, Axel, I997, La lucha por el reconocimiento, Crítica, Barcelona.

Jessop, Bob, 1999, Crisis del Estado de Bienestar. Hacia Una nueva teoría del Estado y sus consecuencias sociales, Siglo del Hombre Editores/Facultad de Derecho y Ciencias Políticas/Facultad de Ciencias Económicas/Universidad Nacional de Colombia, Colombia.

Lara Klahr, Marco y Francesc Barata, 2009, Nota roja. La vibrante historia de un género y una nueva manera de informar, Debate, México.

Loaeza, Soledad, 20I0, Acción Nacional. El apetito y las responsabilidades del triunfo, El Colegio de México, México.

Maldonado, Salvador, 2010, Los márgenes del Estado mexicano. Territorios ilegales, desarrollo y violencia en Michoacán, El Colegio de Michoacán, México.

Mattelart, Armand, 2009, Un mundo vigilado, Paidós, España. Migdal, Joel S., 20I I, Estados débiles, Estados fuertes, Fondo de Cultura Económica, México.

Muchembled, Robert, 2010, Una historia de la violencia. Del final de la Edad Media a la actualidad, Paidós, Madrid.

Navarro, Vicenc, 2000, Globalización económica, poder político y Estado del bienestar, Ariel, Barcelona. 
Reflexiones sobre la violencia y vulnerabilidad en México

Nikolic, Milos, 1995, The causes of the breakdown of "real-

Bibliografía socialism", UNAM, México

Offe, Claus, 1996, Partidos Políticos y Nuevos Movimientos Sociales, Editorial Sistema, Madrid.

Palidda, Salvatore, 20I0, "Política del miedo y decadencia de la esfera pública”, en C. Fernández Bessa, H. Silveria Gorski, G. Rodríguez Fernández y I. Rivera Beiras (eds.), Contornos bélicos del Estado securitario. Control de la vida y procesos de exclusión social, Anthropos, Barcelona.

Polanyi, Karl, 2003, La Gran Transformación. Los orígenes politicos y económicos de nuestro tiempo, Fondo de Cultura Económica, México.

Ravelo, Ricardo, 20I I, El narco en México. Historia e historias de una guerra, Grijalbo, México.

Rivera Beiras, Iñaki, 2010, "Violencia estructural e institucional, crímenes de estado y guerra. Una 'nueva' ruptura epistemológica en la criminología”, en C. Fernández Bessa, H. Silveria Gorski, G. Rodríguez Fernández y I. Rivera Beiras (eds.). Contornos bélicos del Estado securitario. Control de la vida y procesos de exclusión social, Anthropos, Barcelona.

Rodríguez Fernández, Gabriela, 2010, "Lo cotidiano del control en la gubernamentalidad liberal del siglo XXI: una lectura desde Foucault, treinta años después”, en C. Fernández Bessa, H. Silveria Gorski, G. Rodríguez Fernández y I. Rivera Beiras (eds.), Contornos bélicos del Estado securitario. Control de la vida y procesos de exclusión social, Anthropos. Barcelona.

Steger, Manfred B., y Ravi K. Roy, 20 I0, Neoliberalismo. Una breve introducción, Alianza Editorial, España.

Tilly, Charles, 2007, Violencia Colectiva, Hacer editorial, Barcelona.

Torres, Jorge, 2008, Nazar, la historia secreta. El hombre detrás de la guerra sucia, Debate, México. 
Miguel Ángel Vite Pérez

Bibliografía $\quad$ Trombadori, Duccio, 2010, Conversaciones con Foucault. Pensamientos, obras, omisiones del último maître-à-penser, Amorrortu, Buenos Aires.

Turati, Marcela, 20I I, Fuego cruzado. Las víctimas atrapadas en la guerra del narco, Grijalbo, México.

Wacquant, Loïc, 2000, Las cárceles de la miseria, Manantial, Buenos Aires.

, 2005, "América como profecía de autocumplimiento", en Loïc Wacquant (dir.). Repensar los Estados Unidos. Para una sociología del hiperpoder, Anthropos, Barcelona. —_, 2007, Los condenados de la ciudad. Gueto, periferias y Estado, Siglo XXI, Buenos Aires.

_ 2010, Las dos caras de un gueto. Ensayos sobre marginalización y penalización, Siglo XXI, Buenos Aires.

Zizek, Salavoj, 2009, Sobre la violencia. Seis reflexiones marginales, Paidós, Barcelona. 